\title{
The Government of Israel and the Health Care of the Negev Bedouin under Military Government, 1948-1966
}

\author{
SHIFRA SHVARTS, JEFREY BORKAN, MOHAMAD MORAD, \\ MICHAEL SHERF*
}

\begin{abstract}
Introduction
Bedouin Arabs in Israel are a Muslim society undergoing dramatic social change. The Bedouin have lived in the Negev desert since the sixth century, having migrated there from the Arabian Peninsula. In the course of the last five decades this traditionally nomadic/semi-nomadic population has undergone rapid modernization and urbanization, and today approximately 120,000 Bedouin Arabs live in the Negev. ${ }^{1}$ Traditionally herders and farmers, only about 5 per cent of the Negev Bedouin are still semi-nomadic tent dwellers. ${ }^{2}$ Most families are sedentary, living in sub-tribal groups in shacks and houses. The Negev Bedouin population has the lowest socio-economic rating of all localities and social groups in Israeli society. ${ }^{3}$

Even as late as 1917, when Ottoman rule over the region was concluded at the end of the First World War, modern medical services for the rural population were rare and mostly inaccessible, except for infrequent and unscheduled visits by a physician. ${ }^{4}$ Although the British made some limited attempts to introduce western health care to the Negev Bedouin Arabs during the Mandate Period (1917-48), their efforts were largely confined to preventive services and hygiene. However, by the mid-1930s there was a small eight-bed hospital in Beer Sheva and four clinics in the Negev region. ${ }^{5}$ None the less, these meagre services and personnel were totally incapable of providing for the health needs of the Bedouin population, the majority of whom still lived on the periphery of settlement in the country. ${ }^{6}$

* Shifra Shvarts, PhD, Jefrey Borkan, MD, PhD, Mohamad Morad, MD, Michael Sherf, MD, MPH. Address for correspondence: Shifra Shvarts, PhD, Department of Health Management, Faculty of Health Sciences, Ben Gurion University of the Negev, Beer Sheva 84105, Israel; e-mail: shvarts@bgumail.bgu.ac.il.

The authors acknowledge with appreciation the special help of Nurit Barak, of Ben Gurion University, with this paper, and the helpful suggestions of Prof. S Kunitz and Prof. D Mukamel, University of Rochester, NY; Many thanks also go to $\mathrm{H}$ Galai and N Sperber, Israel, for their contributions to the translation and organization of the article.

${ }^{1}$ The Negev is the southern, semi-arid part of Israel constituting approximately 50 per cent of

the country's area. Statistical Yearbook of the

Negev Bedouin, Dec. 1999, No. 1, pp. 29-30.

${ }^{2}$ J A Borkan, M Morad, S Shvarts, 'Universal health care? The view of Negev Bedouin Arabs on health services', Health Policy and Planning, 2000, 15 (2): 207-16, p. 207.

${ }^{3}$ Statistical Yearbook of the Negev Bedouin, op. cit., note 1 above, p. 6.

${ }^{4} \mathrm{~N}$ Reiss, The health care of the Arabs in Israel, Boulder, CO, Westview Press, 1991, pp. 1-35.

5 'Arif al-'Arif, Shevtei HaBedouim BeMachoz Beer Sheva (The Bedouin tribes in Beer Sheva district), Jerusalem, Ariel, and the Joe Alon Center, Kibbutz Lahav, rev. ed. 2000, p. 219.

${ }^{6} \mathrm{H}$ Tal, Letoledot Harefua Banegev, 1948-1970 (On the history of the medical services in the Negev), Beer Sheva, Ben Gurion University of the Negev, 1993, pp. 159-76.
\end{abstract}




\section{Shifra Shvarts, Jefrey Borkan, Mohamad Morad, Michael Sherf}

Following the establishment of an independent Israeli state in 1948, the Israeli government saw fit to relate specifically and separately to the health needs of its entire Arab population. For that purpose, a special Minorities Department was established within the Ministry of Health. In the 1950s, however, the government closed the department, claiming that the Arab community had by then merged into the social structure of the general population. The new approach was to deal with the Israeli Arab population in a manner consistent with long range planning for the general population. ${ }^{7}$ But the situation of the Negev Bedouin Arabs was more complicated than this approach allowed for. During the first two decades of Israeli rule (1948-66), the Bedouin were governed by a military administration, ${ }^{8}$ which significantly restricted the geographical mobility of this previously semi-nomadic people, while providing only rudimentary local services, including health services.

The purpose of this study is to trace the development of Israel's official health policy towards the Bedouin in the first two decades of statehood, from 1948, when the Negev Bedouin lived under a newly established military government, until the abolition of military rule in 1966. The study is based on archival material from the period, including parliamentary protocols, annual reports of the State Comptroller, articles, operational reports of Kupat Holim (the General Sick Fund), interviews and governmental reports describing health policy vis-à-vis the Bedouin sector.

\section{Health Services for the Bedouin of the Negev, 1948-1955}

The establishment of the State of Israel in May 1948 prompted some of the Bedouin tribes to migrate to Egypt and Jordan from the Negev, which had been included in the Jewish state under the UN Partition Plan of 29 November 1947. Out of a total Bedouin population in the Negev of about 65,000 prior to 1948 , approximately 11,000 remained. ${ }^{9}$

Shortly after the outbreak of the War of Independence, the Israel Defence Forces placed the Negev under military government, ${ }^{10}$ requiring special permits for entry

\footnotetext{
${ }^{7}$ Israel Ministry of Health, Health services in Israel, publication no. 163, Jerusalem, Government of Israel Press, 1968.

${ }^{8}$ This abnormal state of affairs, imposition of selective military government by a democratic country, should be viewed in its historic context. The 1948 War of Independence was an armed conflict that began with six months of fierce civil war between Palestinian Arabs and Jews prior to invasion of the country in May 1948 by the armies of the neighbouring Arab countries. It was the culmination of the protracted rivalry between the Arab and Jewish national liberation movements, which was marked by sporadic violence $(1921,1929,1936-39)$ precipitated by Arab resistance to Zionist aspirations. Moreover, for most of the first decade of military government (1948-56), Israel was contending with social and economic upheaval in the wake of war and mass immigration, and the socio-economic and political instability was
}

exacerbated by the problem of the insecure borders. This period was characterized not only by widespread illicit smuggling but also by frequent acts of sabotage and a series of murderous attacks on Jewish civilian settlements and public transport by infiltrators from across the borders, particularly in the Negev. E Marx, Bedouin of the Negev, Tel Aviv, Reshafim, 1974, pp. $38-41$.

${ }^{9}$ Marx notes 55,000 to 65,000 before 1948 , and about 11,000 in 1953. Marx, op. cit., note 8 above, p. 17, table 1, p. 18. Michael Hanegbi, military governor of Beer Sheva, noted 13,000 Bedouin; Tuvyahu Archives, Hanegbi Files, Ben Gurion University, Beer Sheva.

The number of Bedouin mentioned in the Palestine Post on 16 Sept. 1949 was 38,000.

${ }^{10}$ The Arabs of Galilee, the Triangle region and the Sharon were also placed under military supervision. Cities with mixed Arab and Jewish populations were not under military government. 
into or exit from specially designated areas. The issue of permits was the prerogative of the military governor alone. While some Bedouin tribes remained on their land, others were concentrated, through forced migration, in an area that constituted a mere 10 per cent of the terrain in which they had previously enjoyed freedom of movement. In addition, they lost crops and livestock at a time when throughout the country there was a great shortage of food of all kinds. All this had a profoundly detrimental effect on their nomadic lifestyle. As a consequence of these restrictions, the Bedouin sheikhs were dependent on the military authorities and under the control of the military governor, who gave them responsibility for the distribution of transit permits and the registration of births, marriages and deaths within their tribes, for which they were paid." Another result was the limitation of access to medical assistance at the first aid clinic in Beer Sheva. ${ }^{12}$

The pre-independence Jewish community had already established its own extensive medical care system throughout central and northern Palestine, but the Negev remained an undeveloped hinterland where medical services were far less developed. In 1949, a military hospital was opened in Beer Sheva under the auspices of the Israel Defence Forces Medical Corps, but it was primarily designed to serve military government personnel and treated only emergency cases among the Bedouin. Instead, makeshift first aid clinics were established near each of the four military government posts.

With the arrival of Israeli forces in the northern Negev, the provisional government of Israel, still engaged in a war for survival of the fledgling state, established a new "Minorities Department" within the Ministry of Health, headed by Dr A Melchi. ${ }^{13}$ Its creation was motivated by an "enlightened" policy aimed at providing medical services, where they had not previously existed, for minority populations, including all Israeli Arabs. During its first year of operation, the Minorities Department provided first aid services to the Bedouin at the military government headquarters in Beer Sheva. Concurrently, the Ministry of Health opened a regional office in Beer Sheva, and the first medical service for the Bedouin community, Mobile Clinic No.1, was inaugurated in March 1949. ${ }^{14}$ The rather complicated arrangements required to establish this modest service reflected the conditions prevailing in Israeli society at the time. The War of Independence had just ended, and the flood of immigration that doubled the population of the drained and war-torn young state severely strained its financial and material resources. All goods, including food, clothing and petrol, were strictly rationed.

Records of the Ministry of Health's Minorities Department reveal that it planned to create four such mobile clinics in Israel, all operating out of ambulances, one of which was to serve the Bedouin of the Negev. At the same time, the Jewish Society for Humane Service continued to develop plans to expand its medical services to

\footnotetext{
${ }^{11}$ The registration of births, marriages and deaths was a paid service the sheikhs provided to their tribes. On the role of the sheikhs in the military government, see Marx, op. cit., note 8 above, pp. 19-20, 38-44.

${ }^{12} \mathrm{H}$ Kozlovsky, 'The medical care of the Negev Bedouin, 1949-1952', Tuvyahu Archives, Kozlovsky Files.
} 


\section{Shifra Shvarts, Jefrey Borkan, Mohamad Morad, Michael Sherf}

the Bedouin of the Negev. A permanent clinic was planned to provide preventive medicine, social services for the needy and a "sick room" for "hospitalizing" and treating special cases requiring close medical supervision. But the plans to establish separate "sick rooms" were dropped on the recommendation of Melchi, who suggested that the Hadassah Medical Organization take responsibility for hospitalizations within its Beer Sheva facility in order to prevent redundancy..$^{15}$ In practice, Hadassah staff refused to hospitalize Bedouin patients for more than two days, and even then only in cases of dire emergency. Longer hospitalization required the transfer of Bedouin patients to Tel Aviv. ${ }^{16}$ Less urgent cases were sent directly to hospitals in the centre of the country. Surgical cases were referred to the Beer Sheva hospital.

The first mission of the mobile clinic was to inoculate Bedouin children against smallpox, and this project was completed in May 1949, despite logistical difficulties. The Bedouin co-operated fully and the inoculation campaign was carried out without opposition. ${ }^{17}$ Dr Henry Kozlovsky, head of Mobile Clinic No. 1, did not specify the percentage of children vaccinated in this campaign but, in his opinion, the main problems of Bedouin children were malnutrition, eye diseases, infectious sores and diarrhoea caused by poor hygiene. In August 1949, six months after the inauguration of the mobile clinic, the Magen David Adom (Israel first aid society) ${ }^{18}$ informed Kozlovsky that the ambulance was being transferred to Haifa. ${ }^{19}$ The focus of medical care for the Bedouin was then transferred to a clinic opened by the Ministry of Health in November 1950, next to the Hadassah Hospital in Beer Sheva. Special emphasis was placed on mother and child services provided by clinic nurses. All of the four first aid clinics, which opened twice a week, were adjacent to the military government offices. Kozlovsky was appointed district health officer by the Ministry of Health and served as sole physician to the Bedouin community until 1955.

The high incidence of tuberculosis among Jewish immigrant populations arriving in the early 1950s prompted the Ministry of Health to initiate a war on TB that continued for a number of years. Its objectives were to locate carriers, inoculate the population and eradicate the disease. In fact, necessity dictated that, due to the higher incidence of tuberculosis among the Bedouin, efforts to X-ray all possible carriers among them had to be even more thorough than those among the Jewish population. ${ }^{20}$ The aim of the anti-TB campaign was not merely to protect the Jewish population from the spread of the disease, it was part of a national policy for improving the health of the entire population. Failure to combat tuberculosis among the Bedouin could have rendered the campaign ineffective.

\footnotetext{
${ }^{15}$ Letter from Dr A Melchi to Henry Kozlovsky, 12 April 1949, ISA, Minorities Department files, 118/7.

${ }^{16}$ Hadassah Medical Organization Report, 'The Beer Sheva hospital 1949-1951', ISA

Minorities Department files, 118/7.

${ }^{17}$ The first report of Mobile Clinic No. 1 to Israel Ministry of Health, 10 April 1949, ISA, Minorities Department files, 118/7.

${ }^{18}$ Magen David Adom (Hebrew for "Red Shield of David"), the Israel first aid society
}

\author{
(equivalent of Red Cross), founded in 1930. In \\ Israel this is the only recognized first aid \\ organization. \\ ${ }^{19}$ Letter from Magen David Adom to the \\ Ministry of Health, 13 Feb. 1951, ISA, Minorities \\ Department files, 118/7. \\ ${ }^{20}$ Report about the minograph, a mobile \\ roentgen machine used to screen for pulmonary \\ tuberculosis in the years 1954-59. ISA, Minorities \\ Department files, $118 / 7$.
}


The Ministry's final report on the eradication of tuberculosis noted that the inadequate living conditions of the Bedouin, tent encampments, poor nutrition and lack of facilities for maintaining elementary hygiene, were the primary sources of the disease. Twelve per cent of the Bedouin suffered from active tuberculosis, six times the rate ( 2 per cent) prevalent in the Jewish community. With 30,000 Israeli pounds allocated for this purpose, a huge sum at the time, the campaign, which continued from 1951 to 1954 , included mass chest X-rays of the Bedouin population performed with a mobile X-ray unit. Those in need of hospitalization were referred to the Hadassah Hospital in Beer Sheva, or even to the government operated Assaf Harofeh Hospital outside Tel Aviv.

Despite the campaign, difficulties were encountered in treating tuberculosis among the Bedouin. ${ }^{21}$ According to a Ministry of Health report, the primary reason for failure was that 30 per cent of the Bedouin failed to return for periodic check-ups due to difficulties in obtaining travel permits from the military governor. ${ }^{22}$ Sixty per cent refused to be hospitalized or left hospital without prior notice and disappeared, abandoning treatment with the first improvement in their condition, in contravention of doctor's orders.

In general, there were a number of reasons for neglect of curative care among the Bedouin; budget constraints, the low priority assigned to Bedouin health services by the young Israeli State, lack of health legislation, and obstacles linked to the military administration. All services for the Bedouin had to be established anew after 1948, and in many areas, especially in the Negev, facilities available to Jews were also still primitive in 1955. Hence, the state of Bedouin health services was not exceptional in Israel at that time. It should be emphasized, however, that the problem of providing health services to the Bedouin was exacerbated by the logistical difficulties and great expense involved in reaching the highly dispersed population, whose own ability to visit the urban health centres was restricted by the military governor.

The 1950s in Israel were marked by continuing and severe economic hardship. The country was absorbing hundreds of thousands of Jews from surrounding Arab countries and 100,000 Holocaust survivors from Europe. Israel had to cope, both on an emotional and an economic level, with the loss of 1 per cent of the Jewish population: 6,000 Jews fell in the War of Independence out of a population of 600,000 . In addition, from 1950 to 1956 , the government had to contend with armed infiltrators and saboteurs on the periphery, particularly in the Negev region, bordered by Egypt on one side and Jordan on the other.

In 1951, development of the Negev was transferred to the Ministry of Agriculture and then, in 1952, to the Ministry of Finance. The 1951 annual report of the State Comptroller pointed out that this transfer from ministry to ministry caused serious delays and created obstacles in the development of the region and of the Bedouin

\footnotetext{
21 'A summary of the TB problem', Israel Ministry of Health, Minorities Department, 1959, ISA, Minorities Department files, 118/7.

${ }^{22}$ Ibid.; B J Ben Assa, 'TB among the Negev Bedouin', Beriut Hatzibur (Public Health), 1962, no. 5, pp. 333-7, p. 335; idem, 'Vital statistics of
}

two thousand sick Bedouin', Harefua (Medicine, Israel Medical Association Journal), 1964, no. 12: 450-3; M Mendes, 'La Tuberculose parmi les Arabs en Israel', Israel TB Convention Reports, Jerusalem, IMD Press, 1959, p. 99. 


\section{Shifra Shvarts, Jefrey Borkan, Mohamad Morad, Michael Sherf}

community in particular. ${ }^{23}$ However, between 1950 and 1954, no questions concerning the health, educational or economic needs of the Bedouin were raised or discussed in the Knesset. Nor was the issue even mentioned in debates on Negev land registration, although most of the land under consideration lay within the area historically traversed by the Bedouin, or was owned by them outright. ${ }^{24}$

It was not only the Bedouin of the Negev that suffered discrimination as a result of geographic isolation. The lack of adequate hospital facilities for the Jewish population in the area also directly affected the Bedouin because of the demand on existing resources that were in short supply. ${ }^{25}$ The problem could have been solved by legislation for a national health insurance system. This, however, did not transpire. In the period under study, public health services in Israel encompassed only voluntary health insurance, through non-profit making public sick funds similar to Kupat Holim, whose contributors were almost exclusively members of the Jewish community.

For the Bedouin, insurance in general and medical insurance in particular were concepts totally foreign to their culture. Moreover, the majority were too poor to provide themselves with medical insurance on a voluntary basis, and in any case most were totally unaware that such an option existed ${ }^{26}$ Bedouin at that time were rarely wage labourers, with the limited exception of seasonal labour in citrus groves, work that could be obtained only with a permit. Health insurance contributions were directly linked to membership of a labour union and involved regular monthly payments by both employer and employee. Thus, an insurmountable financial obstacle to Bedouin participation in the Kupat Holim health insurance scheme existed, side by side with the enormous cultural barrier. ${ }^{27}$

The first significant change in the provision of health services to the Bedouin based on the principle of egalitarian treatment came only with the passing of the Maternal Insurance Law of 1953 and establishment of the National Insurance Institute, which manages Israel's social security system.

\section{The Activity of the National Insurance Institute and Maternal Insurance in the Bedouin Sector}

At the end of 1953, the Knesset passed the Maternal Insurance Law, which stipulated that all new mothers were entitled to a maternity allowance, part of which

\footnotetext{
${ }^{23}$ 'The report of the Israeli State Comptroller for the budgetary year 1951-1952', Report No. 3, 31 Dec. 1952, Jerusalem, Government of Israel Press, p. 48, Knesset Archives. The Israeli State Comptroller is appointed by the government to examine methods of administration, and income and expenditure accounts of government offices. The Comptroller publishes an annual report and enjoys independent status and full professional autonomy.

${ }^{24}$ The Israeli State Comptroller's Report No 3, 1951-52; Report No. 4, 1952-53; Report No. 5 , 1953-54, Jerusalem, Government of Israel Press, Knesset Archives.
}

\footnotetext{
${ }^{25} \mathrm{~S}$ Shvarts, 'The political conflict about the establishment of a central hospital in the Negev', Eyunim, 1995, 5 (5): 388-412.

${ }^{26}$ Reiss, op. cit. note 4 above.

${ }^{27}$ Prof. Haim Doron, interview, Ramat Gan, 28 Mar. 2001. Doron was a family physician in Kupat Holim Clalit in Beer Sheva from 1953 to 1961; from 1961 to 1968 he was the medical director of the Negev Region of Kupat Holim Clalit. See also Moshe Soroka files, IV-104-32a, Labor Archives-Lavon Institute, Tel Aviv. Kupat Holim, the General Sick Fund, was the major public health provider in Israel; Histadruth, the Federation of Labour, was the "Mother" organization of Kupat Holim.
} 
was to be paid to the hospital to cover delivery costs, and part given to the mother, in goods or in cash, to provide the newborn with basic necessities. Implementation of the law was entrusted to the newly established National Insurance Institute. Under this law, public hospitals received payment from the Institute in lieu of billing the mother. The Ministry of Health set a standard fee for deliveries in public hospitals and negotiated payments to other non-public facilities. The balance of the maternity grant was given directly to the mother upon her discharge from the hospital.

The legislation had a far-reaching effect on Bedouin women. Until that time, most had given birth at home in their encampments with the aid of a tribal midwife, and infant mortality was extremely high. Children were not inoculated and new mothers did not receive instruction on modern care of their infants. Not only were hospital deliveries beyond the means of Bedouin women, they were totally foreign to Bedouin tradition. Now free hospitalization and above all a cash grant served as powerful incentives. Bedouin women opted to go to hospital, not so much out of faith in western medical practices as to become eligible for the cash "reward" upon their release from the hospital. ${ }^{28}$

The number of Bedouin women opting for hospitalization increased, but the 100 bed hospital in Beer Sheva faced increasing difficulties and the number of Bedouin women admitted was limited. The opening of the Central Hospital for the Negev in 1960 alleviated the shortage of hospital beds and the number of Bedouin women admitted to the hospital rose considerably. In 1954, only 5 per cent of all women in the Arab sector gave birth in the hospital; by 1960 that number had risen to 54 per cent and was about 2 out of 3 by $1972-73 .{ }^{29}$ Infant mortality dropped from 61 deaths per thousand births to 31 in $1972-73,{ }^{30}$ but it was still double the death rate in the Jewish community in the same year (16.8 per thousand births). ${ }^{31}$

As well as encouraging hospital deliveries, the Ministry of Health operated mother and child clinics ("Tipat Halav"), staffed by a nurse and open twice a week. These clinics provided instruction to new mothers on how to care for their infants, together with well baby care (weighing and periodic examination), immunizations and milk if needed.

\footnotetext{
${ }^{28}$ Prof. Eliyahu Lehman, director of the Hadassah Hospital in Beer Sheva (1950-60) stated that the social security grant was the prime incentive for Bedouin women using the hospital services for deliveries in the 1950s. Interview, April 2001. Dr Jean Fichmann, a paediatrician, who worked among the Bedouin for twenty-five years, and Dr Viola Turek, the medical director of the Negev Region (1960-88) listed two important reasons why the Bedouin used the hospital for deliveries: first, the social security grant; second, the opportunity to get some rest and "some pampering" during hospitalization (4-5 days). They both noted that after only a couple of years the "medical benefits" of western medicine became a major incentive together with the social security grant and the rest. Interview, April 2001. See also Tal, op. cit., note 6 above, p. 174 .
}

\footnotetext{
${ }^{29} \mathrm{G}$ A Lewando-Hundt, 'Patterns of utilization of health services among Negev Bedouin Arabs', working paper, Sede Boker College of Ben Gurion University of the Negev, 1988 , pp. 2-35, p. 26; Israel Central Bureau of Statistics, Statistical Abstract of Israel, 1955, 1960, 1965, 1970, 1975, 1977, Jerusalem, Government of Israel Press.

${ }^{30}$ Lewando-Hundt (op. cit., note 29 above) noted that, with a problem of under-recording, the actual number of deaths per thousand was between 50 and 100; Israel Central Bureau of Statistics noted 45 deaths per thousand in 1965. Israel Central Bureau of Statistics, Jerusalem, Government of Israel Press, 1965.

${ }^{31}$ Lewando-Hundt, op. cit., note 29 above, p. 26.
} 


\section{Shifra Shvarts, Jefrey Borkan, Mohamad Morad, Michael Sherf}

In addition to the Maternal Insurance Law, which promoted the economic advancement of Bedouin women, the National Insurance Law granted a monthly cash supplement to large low-income families. Moreover, the child allowances-monthly government stipends paid to all parents for each child in the family under the age of eighteen-also contributed to improving the living standards of the Bedouin. Over the years, the child allowance became a significant source of income for some Bedouin families. ${ }^{32}$ Moreover, eligibility for such a benefit encouraged the Bedouin to register newborn children on their identity cards, in the hospital after the delivery. ${ }^{33}$

\section{Health Services for the Bedouin of the Negev, 1955-1959}

In April 1955, the Ministry of Health initiated a separate medical service for the Bedouin in Beer Sheva, headed by a full-time physician, Dr Benyamin Ben Assa, ${ }^{34}$ who was assisted by a trained nurse. Curative services, together with mother and child services and consultations in preventive medicine were provided in a clinic adjacent to the Bedouin market, on the outskirts of Beer Sheva. The Bedouin medical service was also responsible for inoculation and medical supervision in outlying areas. The Bedouin were permitted by the military governor to visit Beer Sheva once a week, on market day, and on that day they sought medical assistance at the clinic, a situation that resulted in long queues and lengthy waits. It became clear that the system needed reorganization and expansion, and that this reform required both additional funding and political support.

On 3 November 1955, Israel Barzilai, a member of the Mapam party, replaced Yosef Serlin as Minister of Health. Mapam, a left-wing socialist party with a history of ideology-based activism in the Arab sector, viewed improvement of health services among the Bedouin as a prime objective. On 26 November 1956, Barzilai addressed the Knesset on the health services in the country as a whole, devoting special attention to the problems of health services among the Negev Bedouin. It was the first time that Bedouin health care had been discussed on the floor of the Knesset. Barzilai cited his Ministry's activities in promoting the health of the Negev Bedouin: the opening of general clinics and the mother and child stations that provided instruction for mothers. He stressed the budgetary constraints and logistic problems associated with expansion of these services.

In the ensuing debate, another member of Knesset, Dr Moshe Sneh (Communist) accused the government of deliberately neglecting minority groups. To underscore his point, he cited infant mortality rates among the Bedouin, which were double those among Jews. In a rebuttal, the previous Minister of Health, Yosef Serlin, argued

\footnotetext{
${ }^{32}$ S E Beckerleg, G A Lewando-Hundt, J M Borkan, K J Abu Saad, I Belmaker, 'Eliciting local voices using natural focus groups', Anthropology and Medicine, 1997, 4 (3): 273-88; A Meir, As nomadism ends: the Israeli Bedouin of the Negev, Boulder, CO, Westview Press, 1997, p. 137.

${ }^{33}$ The Knesset Archives, 16 Jan. 1956, pp. 288-95, and 14 Nov. 1956, pp. 261-2.
}

\footnotetext{
${ }^{34}$ Benyamin Ben Assa (1916-76) was born in Holland and came to Israel in 1950 . He replaced Henry Kozlovsky as head of the medical service for the Bedouin in the Negev, a post he held till 1965. After that he offered his private medical service to the Bedouin in his clinic in Beer Sheva. Ben Assa was awarded the Albert Schweitzer Prize for his work.
} 


\section{The Health Care of the Negev Bedouin, 1948-1966}

that there was no intentional neglect of minorities, rather, the problem stemmed from lack of a comprehensive health policy. The debate focused on the financing of health services, on the political issue of national health insurance legislation, and on the competition between private hospitals and Ministry of Health hospitals. ${ }^{35}$

Despite the lack of a comprehensive health policy, Barzilai used his position to strive for improvements in minority health services. The primary obstacle was a lack of trained staff to fill positions in the Arab sector. ${ }^{36}$ The problem of finding additional physicians to work in Bedouin clinics led Ben Assa to request a transfer from Beer Sheva to Jerusalem, arguing that it was impossible to treat a population of 15,000 Bedouin single-handed. Only the entreaties of the Bedouin sheikhs and promises from the Ministry of Health to find an additional physician persuaded Ben Assa to remain at his post. ${ }^{37}$ However, the Ministry failed to find a doctor to reduce the burden on him, and the situation deteriorated further.

In December 1958, Barzilai, as Minister of Health, opened a new clinic for the Bedouin in Beer Sheva. At the same time, the Ministry made an arrangement with the military government that allowed Bedouin who lacked the means to pay for treatment to be admitted to public hospitals. ${ }^{38}$ The Ministry guaranteed it would cover the hospitalization costs.

Hospitalization, particularly of tuberculosis patients, had been a chronic problem since 1948. Because most Bedouin patients were not members of sick funds, the majority were unable to pay for treatment, but Kupat Holim and government hospitals refused to admit them free of charge. The arrangement for free hospital care was, however, of limited value: it did not cover X-rays or expensive medication. Thus, Bedouin were hospitalized but did not undergo all the testing and treatment available. In December 1958, Mapam voiced opposition to the military governor's practice of intervening in decisions on whether hospitalization was necessary and how much the patient should be required to pay, arguing that the governor was not an objective party and the Ministry of Health should set clear criteria and procedures providing equal access to hospitals for all citizens. ${ }^{39}$

Bedouin patients and their families also complained of "sanctions" by Beer Sheva's Hadassah Hospital's secretary, who would not allow the treatment of Bedouin for whom payment had not been arranged. ${ }^{40}$ In general, the Ministry of Health and the military government tried to protect the Bedouin, not always with success. Ministry reports cited only one hospital, Assaf Harofeh, for its particularly positive attitudes toward Bedouin patients. ${ }^{41}$ The number of Bedouin hospitalized nationwide each

${ }^{35}$ The Knesset Archives, 26 Nov. 1956, pp. 315-26.

${ }^{36}$ Reiss, op. cit., note 4 above, pp. $80-1$, and the Knesset Archives, 20 Nov. 1956, p. 293.

${ }^{37}$ M Arzieli, ' 15000 Bedouins without a physician', Ha'aretz, 20 Mar. 1958, p. 12.

${ }^{38} \mathrm{M}$ Arzieli, 'New clinic for Bedouins in the Negev', Ha'aretz, 20 May 1958, p. 11.

${ }^{39}$ The Knesset Archives, 24 Dec. 1958, pp. 654-5, and 26 June 1956, p. 2115.

${ }^{40}$ Report No. 17 of the Medical Service for Bedouins in the Negev, 1 Sept. 1959 to 1 Jan.
1960, ISA, Minorities Department files, 118/7, and letter from A Paul, the district physician, to B Ben Assa, 21 Feb. 1961, ISA, Minorities Department files, 118/7.

${ }^{41}$ Letter from Malcha Freedman, Deputy of District Department of the Ministry of Health in Beer Sheva, to the Curative Care Department of the Ministry of Health in Jerusalem, 18 May 1960, ISA, Minorities Department files, 118/7. 


\section{Shifra Shvarts, Jefrey Borkan, Mohamad Morad, Michael Sherf}

month averaged between 26 and 42, the overwhelming majority of them in Beer Sheva's Hadassah Hospital. ${ }^{42}$

The problem of hospitalization of Bedouin patients was significantly alleviated with the opening of the Central Hospital for the Negev in Beer Sheva in 1960, a facility built, owned and operated by Kupat Holim. Before it was opened, an agreement was reached between the Minister of Health, Barzilai, and Moshe Soroka, the administrative director of Kupat Holim, whereby, in return for permission to build the Central Hospital, all Bedouin would be admitted irrespective of means. ${ }^{43}$

This agreement marked the first serious attempt by a minister of health to solve, at an institutional level, the problem of providing the Bedouin with hospital care near to their homes. In a letter to the Beer Sheva district physician, the head of medical services in the Ministry of Health, Dr Bernard Cohen, wrote, "In the future, Bedouin will be hospitalized only in Beer Sheva. They will be sent to government hospitals in the North [Assaf Harofe] only if there is no suitable department to treat them in the Beer Sheva hospital." ${ }^{44}$

Mobilizing nursing and administrative personnel to operate the Bedouin clinics was also a problem. It was hard to find a suitable nurse, since the post required fluency in Arabic and outstanding organizational skills. In addition to operating the clinic in Beer Sheva, the nurse was also responsible for supervising the four local clinics in the area under military government and for instructing the Bedouin medical orderlies who worked as auxiliary personnel in the clinics. Moreover, the job called for sensitivity to Bedouin traditions and culture in dealings with patients. In December 1959, the chief nurse in the Beer Sheva clinic was dismissed for inappropriate behaviour and insensitivity toward Bedouin patients. During the same period, a report by the Minorities Department of the Ministry of Health noted that the minorities' officer and two clerks had been relieved of their duties on the same grounds. It was difficult to find suitable candidates to replace them.

To solve the shortage of personnel, Ben Assa began training Bedouin as medical orderlies and practical male nurses. ${ }^{45}$ In April 1960, the first Bedouin practical male nurse was qualified after completing a two-year course. The male nurses were integrated into the clinics, serving as auxiliary staff to the registered nurse.

\section{The Bedouin Medical Services, 1960-1966}

Between 1957 and 1960, the Negev suffered from an extended drought that severely affected the Bedouin living under military government. Camels and sheep were left without pasture. The media reported hunger among Bedouin tribes and the subject was raised in the Knesset, although the Ministry of Health claimed that there was no genuine famine, but rather a temporary state of distress ${ }^{46}$ In an extraordinary

\footnotetext{
${ }^{42}$ Report No. 17, op. cit., note 40 above.

${ }^{43}$ As a condition for the establishment of the central hospital in the Negev, I Barzilai, the Minister of Health, specified that it must provide medical services to soldiers.

${ }^{44}$ Letter from Dr B Cohen to the district physician in Beer Sheva, 27 Mar. 1960, ISA, Minorities Department files, 118/7.
}

\footnotetext{
45 "Practical nurses" are not registered and receive a shorter training than registered nurses. In the past, in many peripheral areas, practical nurses took the place of registered nurses when no registered nurse was available.

${ }^{46} \mathrm{M}$ Arzieli, 'No hunger among Bedouins', Ha'aretz, 24 Mar. 1960, p. 7.
} 
measure, the Israeli government allowed the Bedouin to migrate northward, beyond the jurisdiction of the military.

The depletion of herds had a harsh effect on the economic circumstances and health of the Bedouin. Among infants and children, numerous cases of malnutrition were seen. Under normal circumstances, Bedouin children were nursed for an extended period, as long as their mothers had milk. ${ }^{47}$ Changes in nutrition among the mothers, as a result of the drought, adversely affected the health of the children, and the number of cases of malnutrition-induced anaemia grew, leading to the hospitalization of large numbers of infants in the Central Hospital of the Negev in Beer Sheva. ${ }^{48}$ To alleviate the plight of the Bedouin, the Ministries of Health and Welfare provided families with monthly stipends of up to 60 Israeli pounds a month. At the same time, the Ministry of Education budgeted for milk distribution to Bedouin children within the public school system; over a period of two months some 550 containers of bottled milk ( 2775 cups) were distributed to schoolchildren. The campaign was well received; schools reported 100 per cent attendance throughout the two-month period. ${ }^{49}$ The Bedouin also received dry goods, flour, rice, powdered milk, eggs and oil, and those suffering from tuberculosis received an enriched ration.

The special distribution programme was scheduled to last six months. However, the continuation of the drought and the increase in the number of malnourished Bedouin led to a worrying rise in the incidence of tuberculosis to a rate four times higher than that among the Jewish population. The Ministry of Health was obliged to renew its campaign against the disease. ${ }^{50}$ Mantoux tests were conducted en masse, and children were vaccinated. In June 1960, Ben Assa called an emergency meeting at the regional office of the Ministry of Health in Beer Sheva and warned that he could not keep the outbreak of tuberculosis under control. A committee was formed to prepare a suitable response. ${ }^{51}$ The programme adopted called for vaccination of 17,000 Bedouin, with the assistance of auxiliary nursing staff and in the presence of outside observers. Also, in order to protect the population of Beer Sheva from

\footnotetext{
${ }^{47}$ Breast-feeding lasted for eighteen months for a boy and a year for a girl. This was very flexible and weaning often occurred in the spring. M R Forman, G Lewando-Hundt, D Towne, B Graubard, B Sullivan, H W Berendes, B Sarov, L Naggan, 'The forty-day rest period and infant feeding practices among Negev Bedouin Arab women in Israel', Medical Anthropology, 1990, 12: 207-16; K Abu-Saad, 'Rapid urbanization and lifestyle, diet and health status changes in Bedouin Arabs of southern Israel', a preprint, publication of the Daniel Abraham International Center for Health and Nutrition, Ben Gurion University, Beer Sheva, summer 2001, pp. 1-20.

${ }^{48} \mathrm{~B}$ Ben Assa, 'The medical work among the Bedouins', Harefua, 1961, no. 9: 217-19; M Arzieli, 'Malnutrition among the Bedouin children', Ha'aretz, 19 Oct. 1964. p. 5.

49 'Report of milk distribution among Bedouin schoolchildren', p. 2, ISA, Minorities Department files, 118/7. This maximum attendance rate during
}

these two months, was a unique phenomenon, since, as a rule, school attendance among the Bedouin was very low. I Abu-Saad, 'Minority higher education in an ethnic periphery: the Bedouin Arabs', in O Yiftachel and A Meir (eds), Ethnic frontiers and peripheries: landscape of development and inequality in Israel, Boulder, CO, Westview Press, 1998, pp. 269-86; A Meir and D Barnea, The development of the Negev Bedouin educational system, Beer Sheva, Dept. of Geography, Ben Gurion University of the Negev, 1985, pp. 18-20; 'Kupat Holim in the Negev', Davar, 25 May 1961, p. 8. Only a few girls were included in the milk distribution as it was not until 1972, when female teachers started being employed in Bedouin schools, that the numbers of girls attending school rose.

so 'Report of milk distribution among Bedouin schoolchildren', op. cit., note 49 above, p. 2.

${ }^{51}$ Ibid. 


\section{Shifra Shvarts, Jefrey Borkan, Mohamad Morad, Michael Sherf}

possible infection, the Ministry of Health decided to vaccinate all Beer Sheva residents under the age of thirty who had not previously been vaccinated, in the hope that this would stop the spread of the disease and reduce its incidence among the Bedouin. Budgetary constraints facing the Ministry in its activities among the Bedouin were not limited solely to the tuberculosis campaign. Those Bedouin whom the military governor judged able to contribute to the cost of hospitalization paid only a pre-set fee, irrespective of the number of days spent in the hospital or the nature of the care they received. On the other hand, the entire hospital bill for indigent Bedouin was covered by the Ministry of Health. Since most Bedouin were categorized as unable to pay, they were often in no hurry to leave hospital. Kupat Holim, assured of payment under any circumstances, was liberal in admitting patients and lax in discharging them. This policy subsequently led to extremely high expenditure.

To address the problem of resources wasted on unjustified hospital stays, Dr A Paul, acting deputy director of the Ministry of Health's Beer Sheva regional office, ${ }^{52}$ demanded that Bedouin with means to do so should pay according to the length of their stay in hospital, rather than a fixed fee, thus providing an incentive for them to leave the hospital on time. In addition, the military governor asked Ben Assa to examine the financial standing of each Bedouin seeking hospitalization in order to limit the number of unnecessary admissions of those who were destitute. ${ }^{53}$ Only in 1964, however, after three years of deliberation, did the Ministry agree that Dr Amos Arnan, the permanent district physician for the Negev, ${ }^{54}$ should be permitted to gather evidence about the finances of each family within the domain of the military government. Arnan would decide before and not after hospitalization whether a patient could pay. Kupat Holim did not involve itself in these deliberations at all, since full coverage of the hospitalization costs of Bedouin in its Beer Sheva facility was already assured. ${ }^{55}$

While questions of budget and funding were solved through administrative reform, without any detrimental impact on the quality of medical services to the Bedouin, the problem of recruitment of nursing and medical personnel was far more difficult to overcome. Shortage of trained staff was a major impediment to the development of services.

In March 1961, Dr Y Cohen, head of medical services in the Ministry of Health, requested the assistance of the Jewish Agency (the veteran NGO associated with the World Zionist Organisation that engages in immigration and Jewish settlement activity) in locating an immigrant physician to work with the Bedouin. He made it clear that the Ministry would cover the cost of training. At the same time, the Ministry of Health sent a similar message to the Association of Dutch Immigrants

\footnotetext{
${ }^{52}$ A Paul from Rehovot in Israel replaced A Arnan, the district physician, for a short period while the latter was in the United States. According to Dr Turek, later the district physician, Paul was unrealistic in his expectations, and when Arnan came back the situation improved. Paul's plans, he said, were detrimental to the Bedouin medical service.
}

\footnotetext{
${ }^{53}$ Letter from Paul to the Director of Peripheral Services, 19 June 1961, ISA, Minorities Department Files, 118/7.

${ }^{54}$ Amos Arnan was the district physician in Beer Sheva during 1957-67.

${ }^{55}$ Correspondence between the Ministry of Health in Jerusalem and B Ben Assa, Mar. 1961 to Oct. 1964, ISA, Minorities Department, 118/7.
} 
in Israel, requesting their help in finding a Jewish doctor in the Netherlands who would be prepared to fill the post. It is worth noting that Ben Assa was of Dutch extraction and his work with the Bedouin was well known among the Dutch Jewish community. There was a second Dutch-born physician in Beer Sheva, the paediatrician Dr Wilhelmina Cohen. Dr Jean Fischmann, ${ }^{56}$ who had worked in the Hadassah Hospital in Beer Sheva, accepted the position and began work in the Ministry's medical service for the Bedouin at the end of 1961. She undertook responsibility for mother and child care, health education and preventive medical services (vaccinations, etc.)

The issue of the status of medical services for the Bedouin surfaced in its full intensity in June 1961, when Paul ordered Ben Assa to remove signs with the wording, "The Bedouin Medical Service", from the Beer Sheva and Umm Betin clinics, claiming that legally there was no such entity as the "Bedouin Medical Service". ${ }^{57}$ Ben Assa complied, but appealed against the directive, stating, first, that it was illogical to claim there was no such official service, when in practice the service had operated for six consecutive years; second, that it was incorrect to define the buildings as "clinics", because they provided services other than medical services: arranging hospitalization, organizing special campaigns such as milk distribution to schools, the war on tuberculosis, the training of Bedouin medical orderlies, and so forth; third, that since the Ministry of Health was making efforts to expand services with its mother and child clinics, additional physicians, and so forth, there was no sense in claiming such a service did not legally exist. ${ }^{58}$

Paul rejected the appeal, insisting that the service be defined as operating under the auspices of the regional office. He claimed that Ben Assa was trying to set up a separate service in defiance of the decisions of the Government of Israel. According to Paul, Ben Assa had circumvented Paul's authority whenever possible and endeavoured to change the status quo by undermining the supervisory role of his office and attempting to free himself from dependence on the district physician. ${ }^{59}$

The controversy over the status of the medical service for the Bedouin was exacerbated by the initiative of the Minister of Agriculture, Moshe Dayan, promoting permanent settlement of the Bedouin. Dayan claimed that such a move would alleviate their economic plight, which had worsened due to the drought. The majority of the Bedouin rejected this suggestion, fearing it would accelerate government seizure of their lands. Ben Assa's support of their position further undermined the physician's relationship with the Ministry of Health. In a letter to the Minister of Health, Ben Assa wrote: "I must point out that the Bedouin are residents of the southern district under the supervision of the military government. They have problems in agriculture, water management, work, medicine, security and more.

\footnotetext{
${ }^{56}$ Jean Fischmann was born in England, and worked as paediatrician among the Bedouin for twenty-five years. Personal communication, 2 Sept. 1997.

${ }^{57}$ Letter from B Ben Assa to the Department of Peripheral Services, 14 June 1961, ISA, Minorities Department files, 118/7.
}

\footnotetext{
${ }^{58}$ Ibid.

${ }^{59}$ Letter from Paul to the Director of Peripheral Services, 19 June 1961, ISA, Minorities Department files, 118/7.
} 


\section{Shifra Shvarts, Jefrey Borkan, Mohamad Morad, Michael Sherf}

Since when do the Bedouin and their problems belong solely to the Ministry of Agriculture? It would be highly desirable to establish a high level committee of experts that can deal seriously with these problems with the active and ongoing cooperation of the Bedouin themselves. Up until now, no one has asked them what they want. I hope the Minister will want to initiate the establishment of a committee of this nature" ${ }^{60}$ There was no response to this letter, no committee was formed, and no one asked the Bedouin whether they wanted permanent settlement.

But the growing needs of the Bedouin could not be ignored. In 1961 the Ministry of Health launched plans to expand services, with more clinics to be established within the area of military administration. It was decided, however, not to build new clinics, but to expand existing ones, until the government decided where permanent settlements for the Bedouin would be located. At the same time, the Prime Minister, Levi Eshkol, ordered the transfer of all Bedouin affairs to his office in order to centralize and co-ordinate treatment, and overcome the lack of integration that had characterized services in the past. The primary motive behind the concentration of Bedouin affairs in the Prime Minister's office was the formulation of a unified policy that would facilitate implementation of plans for permanent settlement. Health issues were addressed only in the context of arrangements for settlement. ${ }^{6}$

According to a memorandum on 'Development of medical services for the Bedouin', prepared by the southern district of the Ministry of Health in 1961, the plan was designed for 20,000 Bedouin. The introduction stressed, first, that it was impossible to raise the health standards of the Bedouin as long as they remained scattered over a wide geographic area in transitory tent encampments affording insufficient shelter, lacking potable water, and adequate education facilities. Second, it was imperative to settle the Bedouin in solid stone structures in villages or cities in one or several locations and to integrate them into the economy of the country as farmers, unskilled labourers or skilled craftsman. Third, a professional, inter-ministerial committee should be established to examine the alternatives, together with experts and people familiar with Bedouin life, including the Bedouin themselves, and to formulate plans for implementation of these recommendations.

The document stressed that anyone who had spent a number of years working in close proximity with the Bedouin must be aware of the government's lack of planning in every aspect of these people's lives. ${ }^{62}$ The Ministry of Health was of the same opinion as the Ministry of Agriculture with regard to permanent settlement of the Bedouin, believing it to be a prerequisite for improving their standard of health, but no one had consulted the Bedouin themselves. This memorandum was the first to attempt to formulate a coherent government health policy.

\footnotetext{
${ }^{60}$ Letter from B Ben Assa to the Minister of Agriculture, Moshe Dayan, 1960 (exact date is missing), ISA, Minorities Department files, 118/7.

${ }^{61} \mathrm{M}$ Arzieli, 'Ben Gurion appointed a committee to study the Bedouin subject', Ha'aretz, 8 Jan. 1963 , p. 2 , and the Knesset Archives, 4 Dec. 1963, pp. 400-2.
}

\footnotetext{
${ }^{62}$ Memorandum from the District Department of the Ministry of Health regarding the development of health services for Bedouins, 1961, ISA, Minorities Department files, 118/7.
} 
The programme's guidelines called for:

1. Doubling the nursing and medical staff within the framework of existing clinics;

2. Introducing social workers into welfare services for Bedouin;

3. Expanding mother and child care clinics;

4. Posting a paediatrician at mother and child care stations;

5. Establishing service desks within the domain of the military government;

6. Operating an ambulance to provide medical assistance;

7. Setting up a doctor-nurse team responsible for fighting tuberculosis, including the location of active cases, transporting patients for hospitalization and continuous observation of families exposed to the disease.

In the long term, the plan called for four physicians, seven nurses, three clerks, one laboratory technician, one social worker, and three manned ambulances, all for a population of 20,000 people. The obstacles to the realization of the programme were the lack of a budget, a timetable, and of adjustments for natural population growth.

In 1961, when the memorandum was composed, there were 17,000 Bedouin; by 1964, when the plan was implemented in part, their number had risen to 20,000 (almost double the 1948 figure of 11,000). As a result, there was a growing gap between the slowly developing health services and the growing needs of the population, resulting from the rapid natural growth rate of the Bedouin community.

\section{Kupat Holim and Health Services for the Bedouin in the Negev}

In December 1961, Kupat Holim began providing ambulatory health services to the Bedouin of the Negev. At that time, Kupat Holim, the primary health fund in the country, provided health services to 80 per cent of Israel's inhabitants. Medical coverage through membership of the organization was contingent on membership of the Labour Federation, the founder and owner of Kupat Holim, which also granted protection of employees' rights, pensions, annual vacations, workers' compensation in cases of work-related accidents, maintenance of agreed working conditions, and an overview of salary agreements.

In the 1950s, Kupat Holim focused its operation on the Jewish community, including the extension of health services to new immigrants. In these years, the health organization fought to maintain its autonomous status as a Labour Federation controlled institution, fiercely opposing attempts by the Minister of Health, Yosef Serlin, and the Prime Minister, David Ben-Gurion, to nationalize the health services.

In the early fifties, the Fund operated in Beer Sheva and was the only health provider offering ambulatory services to Jews living in Beer Sheva and outlying Jewish agricultural settlements throughout the Negev, mostly populated by new immigrants. The opening of the Central Hospital for the Negev in Beer Sheva in 1960 and the agreement with the Ministry of Health on the hospitalization of Bedouin enhanced Kupat Holim's status in the Negev and prompted it to open its membership to the Bedouin sector.

From a political standpoint, Kupat Holim viewed extensive penetration of the "market" with services for the Bedouin as a means of enhancing the organization's power and hegemony as Israel's leading health service provider. A similar position 


\section{Shifra Shvarts, Jefrey Borkan, Mohamad Morad, Michael Sherf}

was adopted by the Labour Federation, whose leaders viewed as a positive development the increase in Federation membership through admission of hundreds of Bedouin. In December 1961, Kupat Holim opened a clinic for Bedouin in Beer Sheva. By December 1963 there were already 485 Bedouin members of Kupat Holim, among them Sheikh Hammad Abu Rabia, the richest of the Bedouin sheikhs. At the beginning of 1964, there were 600 members, and the Fund was providing health services to 2,000 Bedouin and their families. Shortly after opening its first clinic for Bedouin in Beer Sheva, Kupat Holim decided to establish a clinic in Umm Betin as well, adjacent to the Ministry's Bedouin medical services clinic. Ben Assa was opposed to this move, arguing that two separate and competitive systems were wasteful and redundant. In his view, maintenance of two systems was the worst of all options. ${ }^{63}$ Ben Assa's comments prompted the director general of the Ministry of Health to suggest to Kupat Holim that they collaborate on the opening of the Fund's clinic for Bedouin. In December 1964, the two bodies agreed that Kupat Holim would not open clinics without co-ordinating plans with the Ministry, and that, in locations where clinics were operated by the organization, it would provide services to uninsured Bedouin, with payment assured by the Ministry. ${ }^{64}$ This agreement opened the door for unlimited expansion of health services to the Bedouin. Concurrently, outpatient clinics at the Central Hospital of the Negev were opened to Bedouin patients in need of specialists.

As the Bedouin settled in permanent locations and military rule drew to a close, the Fund intensified and broadened its activity in the Bedouin sector. By 1966, when the military government was abolished and the first Bedouin town was built, the Fund was the only health organization providing health services to the Bedouin in the Negev. In 1972, the Ministry of Health reached an arrangement with Kupat Holim whereby the Ministry's health service clinics were incorporated into the framework of the Fund's clinics. The Ministry continued to operate mother and child stations. Thus, within the Bedouin community, curative medicine was placed entirely in the hands of Kupat Holim. This situation prevailed until 1995, when Israel passed a National Health Insurance Law, and competition for membership led the other three sick funds to open clinics in the Bedouin sector as well.

\section{Bedouin Medical Services in 1966, at the Close of Two Decades of Military Government}

In 1964 the level of medical services for the Bedouin in the Negev deteriorated. Dr Ben Assa, who had been director of health services and physician to the Bedouin since 1955, resigned. A series of temporary appointments followed, until curative care was transferred to Kupat Holim in 1972. All the other functions that Ben Assa had performed for the Bedouin were closed down, including an advisory service on

\footnotetext{
${ }^{63}$ Letter from B Ben Assa to A Arnan, 9 Jan. 1964, ISA, Minorities Department files, $118 / 7$.

${ }^{64}$ Letter from Dr Eliyahu Mani, Director of Peripheral Services, to the Department of
}

Peripheral Services concerning the contracts signed by him and Stephan Graik of the central committee of Kupat Holim, ISA, Minorities Department files, 118/7. 
contact with the outside world, the formulation of a local health policy targetting the special health needs of the Bedouin community, health education and information, academic research, and co-ordination with the military government.

The resignation of the physician who had been "the Bedouin's champion" in the health system, faithfully guarding their best interests, had a detrimental effect on the Bedouin. Some 20,000 people living in encampments were left without health services. "The four clinics that were opened with much pomp and ceremony stand closed, gathering dust", wrote the newspaper Ha'aretz. Criticism mounted, particularly after publication of press reports of the dispatch of Israeli physicians and medical supplies to countries in distress in Africa. Sheikh Hammad Abu Rabia commented, "Israel sends doctors to Africa and we, the loyal citizens of the State don't have even one doctor". 65

In an interview with Ha'aretz, Ben Assa declared that not only the Ministry of Health was to blame, but the medical community as well, because doctors were unwilling to work in the Negev. When four public tenders were published by the Fund, only one doctor applied. Ben Assa stressed that the problem of attracting medical staff was common to the Negev as a region, not specific to the Bedouin as a minority. ${ }^{66}$

During the recession that struck the Israeli economy in the sixties, leading to an unemployment rate of 10 per cent in early 1967, the avoidance of the Negev by physicians in 1965 and 1966 was particularly marked. The recession prompted many Israelis, including physicians, to seek employment abroad, but the posts offered in the Negev remained unfilled.

The political climate in the sixties was not particularly encouraging for the future of Bedouin health care. From 1961 to 1966, the Interior, Health and Welfare ministries were all headed by ministers who were members of the National Religious Party (NRP). Compared with the fifties, and despite the deep economic recession, the government enjoyed relative stability during this period, based primarily on the presence of the NRP in the coalition (which at that time leaned heavily toward socialist-labour values and a welfare state economy). Partisan considerations led NRP ministers to focus their attention on Jewish urban religious communities, neglecting the Arab sector. None exhibited interest in improving health services for the Bedouin. Ministry of Health reports for 1965-66 claimed that the Ministry of Welfare had failed to provide welfare and social work services for the Bedouin and that the Ministry of the Interior had failed to complete the registration of all Bedouin entitled to National Insurance benefits. According to one report, the percentage of Bedouin receiving benefits was extremely low, with many totally unaware of the benefits due to them from the Institute. Objectively speaking, the Bedouin, a low income group burdened by poor health and limitations on personal freedom, clearly deserved special attention in matters of health, education and welfare, but what they received was, in fact, less than adequate.

\footnotetext{
${ }^{65} \mathrm{M}$ Arzieli, 'The Bedouin were left without doctor', Ha'aretz, 14 May 1965, p. 16.
}

\footnotetext{
${ }^{66} \mathrm{M}$ Arzieli, 'Dr Ben Assa, a man with principles', Ha'aretz, 14 Mar. 1965, p. 12.
} 


\section{Shifra Shvarts, Jefrey Borkan, Mohamad Morad, Michael Sherf}

In September 1965, in the shadow of the recession, an inter-ministerial committee was appointed to carry out a plan to settle the Bedouin permanently at three locations. The impetus for permanent settlement derived from security considerations, mainly the preservation of government control of public lands in the Negev. Representatives of the ministries of health and education were not asked to serve on the committee. The State Comptroller noted in his annual report that the Bedouin had not been invited to participate in the decision-making either. Development plans for the three settlement areas were completed in March 1966 and by the end of the year water supply pipes had been laid and access roads built. Parallel with the permanent settlement programme, the Israel Lands Authority inaugurated a programme for leasing land for grazing and agricultural cultivation to Bedouin. This unilateral step, taken without consulting the Bedouin themselves, prompted heated debate in the Knesset, initiated by parliamentary queries from Arab Knesset members. At this time, there were no Bedouin members of parliament.

The final days of military government were characterized by rising tension between the Bedouin and the government of Israel. Bedouin hostility stemmed from plans for permanent settlement, fear of seizure of lands by the government, the paternalistic behaviour of the Israel Lands Authority regarding land use, and the failure of education and health services.

Until military rule was abolished in late 1966, the State Comptroller did not scrutinize the performance of the medical service for the Bedouin in his annual report, except indirectly as part of the Ministry of Health Minorities Department. With the end of military control, the medical service for the Bedouin was classified as a separate subject for examination. This was a significant change. Throughout the era of military government, data gathered within the Bedouin community were included with data for the Arab sector in general, making it difficult to evaluate the true state of affairs of the Negev Bedouin. In fact, at times the situation within the Arab sector as a whole was diametrically different to that prevailing within the Bedouin sector. For instance, statistics showed a significant growth in the number of mother and child stations, treatment clinics and medical centres among the Arabs, while the situation among the Bedouin remained static and even regressed relative to the significant population growth. ${ }^{67}$ The end of military government in December 1966 did not render physicians any more willing to move to the Negev. The medical services for the Bedouin continued to suffer from a severe shortage of trained personnel that prevented expansion to meet the needs of a growing population. On the other hand, the removal of military control did bring about an immediate improvement in the standard of living of the Bedouin and their economic situation. Indirectly, these changes led to an improvement in their health. A significant number of Bedouin chose to join Kupat Holim and take advantage of the services of private physicians, thanks to their improved finances. As a result, there was a drop in the number of Bedouin seeking the assistance of the government-supported medical

\footnotetext{
${ }^{67}$ A report by the Ministry of Health, Minorities Department, Addendum: List of
} 
service, reflecting widespread dissatisfaction of the Bedouin with the quality of free treatment provided by government-run curative services.

However, while these services received low appraisals, the Bedouin valued and cooperated with the Ministry of Health's preventive medicine apparatus, primarily the mother and child stations and vaccination programmes. The State Comptroller found that vaccinations were up to date, despite the lack of health services within the school system. ${ }^{68}$ In response to the State Comptroller's evaluation, the Ministry of Health announced plans to expand preventive medical care for the Bedouin in 1968-69, with a mobile health team and health services in the schools. ${ }^{69}$

\section{Conclusion}

The medical service for the Negev Bedouin Arabs was established with the creation of the State of Israel. The service was inaugurated with a mobile clinic designed to provide curative services, but was transformed rapidly into an institutionalized governmental service engaged in both curative and preventive medicine. The military government and the Minorities Department of the Ministry of Health jointly governed the service. Assigned a low priority on the national agenda, the service suffered historically from discrimination and neglect of the special needs of the Bedouin population. These were exacerbated by practical obstacles, including the problems of treating a dispersed population living on the periphery, not always in accessible locations, and an acute shortage of suitable nursing and medical personnel.

Political instability and partisan politics, the physical and social isolation inherent in the military administration, and the Bedouin's location on the geographical and political periphery, all prevented the organization of adequate medical services for them. To these difficulties must be added the economic and security problems facing Israel in its early years. The limited resources of a country over-extended by war and mass immigration made it impossible to channel sufficient resources for the needs of the Bedouin community and grant them the attention they required. Moreover, lack of experience and the disinclination of the medical community to undertake responsibility for the needs of the Bedouin took their toll, while the reluctance of the Bedouin community to accept western medicine also weakened the system.

The introduction of maternal insurance, which encouraged hospital deliveries, together with mother and child stations, and the "penetration" of the Bedouin sector by Kupat Holim were all positive factors that contributed to an improvement in the quality of health services provided to the Bedouin. The opening of the Central

\footnotetext{
${ }^{68}$ The evaluation of the Comptroller was based on the clinics' records. Other sources mentioned that about 37 per cent of the Bedouin children were not immunized at all and, of those that did attend the clinics, only 18 per cent were fully immunized at the end of the year. LewandoHundt noted that, based on the Ministry of Health team records, between 70 per cent to 80 per cent of the children were immunized. Lewando-Hundt, op. cit., note 29 above, p. 28.
}

\begin{abstract}
For many years the health services in schools consisted of one practical nurse on a moped, and the mobile health team had very limited coverage. Forman et al., op. cit., note 47 above, pp. 207-16.

${ }^{69}$ Sayyid al Sane, community health worker, operates the Mobile Unit for Follow Up Care to Bedouin Arab patients, run by Kupat Holim, based at the Soroka Medical Center. Interview, April 2001, at the Faculty of Health Sciences, Ben Gurion University of the Negev, Beer Sheva.
\end{abstract}




\section{Shifra Shvarts, Jefrey Borkan, Mohamad Morad, Michael Sherf}

Hospital for the Negev and the arrangement for free hospitalization of poverty stricken Bedouin widened the scope of Bedouin medical services and changed the pattern of use of health services by the Bedouin community.

The Achilles heel of the system was the lack of comprehensive government policy and planning. As a result, development of services lagged behind rapid population growth and those services that existed could not function adequately under a growing caseload. Between 1948 and 1964, the Bedouin population virtually doubled, while health services were expanded by only 33 per cent. Despite this, two decades of preventive medicine succeeded in lowering significantly the incidence of viral infections, reducing mortality rates, and improving the general health of the Bedouin.

The institution of military government, entailing restrictions on the movement of the Bedouin, actually contributed to the effectiveness of preventive medicine programmes, allowing medical staff to locate and treat stricken areas and prevent the spread of infectious diseases. When centres of infection became evident, the military governor was capable of mobilizing swift and effective measures to intervene. On the other hand, he lacked professional training in medicine, a weakness that led at times to decisions detrimental to the functioning of health services. The military government helped with the logistics of providing medical services, but violated the civil rights of the inhabitants and prevented their integration into Israeli society. Thus, most Bedouin were unaware of their right to National Insurance benefits for the first eighteen years of their enactment. The interior and welfare ministries claimed that these matters lay within the purview of the military government. As a result, registration of the Bedouin as citizens was delayed, and restrictions on their movement effectively prevented their access to alternative health services beyond the limited services provided by the government. The military government allowed the authorities to register Bedouin lands and formulate a plan for permanent settlement, but did not take any steps to create even a short-term health policy.

Only with the entrance of Kupat Holim into the Bedouin sector in 1962 were equitable health services introduced, and only in 1967 did the State Comptroller address the issue of health services to the Bedouin in his annual report. Even this was done only as part of a larger study that did not reflect the true situation among the Bedouin. It is significant that during twenty years of military rule the Bedouin were never once consulted in debates in the Knesset concerning their health-related needs and desires. Most decisions were taken ad hoc. Improvements were forthcoming only after Bedouin sheikhs mobilized the power of the press or put pressure on the Ministry through the good offices of Ben Assa. Most of the press, including socialist party newspapers, devoted little space to Bedouin issues.

In conclusion, for both objective and subjective reasons and in the absence of a well formulated public policy, Bedouin health issues were assigned a very low priority on the national agenda. The military government delayed the integration of the Bedouin into Israeli society, a situation that was detrimental to the development of health services during the period, and increased the gap between objective needs and actual services developed. This gap has narrowed with the transition to permanent settlement in the past three decades and the economic and social changes that have accompanied this transition. 